\title{
Dinheiro - um meio simbolicamente generalizado da comunicação? Sobre a doutrina do dinheiro na recente sociologia'
}

\author{
Money - a symbolically generalized medium of communication? \\ On the concept of money in recent sociology
}

Heiner Ganßmann

\section{Tradução de Bruno Serrano ${ }^{a}$ (1)}

Não foi Gladstone, como afirmou Marx, que advertira, diante do parlamento inglês, que "nem mesmo o amor tornou os seres humanos tão tolos quanto a ruminação sobre a essência do dinheiro" (MARx, 1961, p. 69). Mas isso não impediu os sociólogos de levarem a advertência a sério. Em todo caso, há muito tempo existe pouco a se relatar da sociologia como digno de nota acerca do tema do dinheiro, principalmente nada que pudesse ajudar os economistas em suas já notórias dificuldades teóricas com o dinheiro. Como sempre, a maldição de von Wiese parece pesar sobre as duas disciplinas.

O antigo Leopold von Wiese (1965, p. 248) - um assim chamado nestor da sociologia alemã - havia proposto uma delimitação, aguçada em sua simplicidade, entre economia e sociologia segundo a qual a economia teria a ver com relações sujeito-coisa, ao passo que a sociologia, com relações sujeito-sujeito. Em contrapartida, todo economista ou sociólogo esclarecido sabe hoje que a questão não é tão simples assim - mas seria uma maldição se, apesar desse saber, não resultasse dessas ciências senão um preenchimento dos escaninhos preparados por von Wiese.

1 GANßMANN, Heiner. Geld - ein symbolisch generalisiertes Medium der Kommunikation? Zur Geldlehre in der neueren Soziologie. Prokla. Zeitschrift für kritische Sozialwissenschaft, v. 16, n. 63, 1986, p. 6-22.N. T.:Heiner Ganßmann (1944-2018) estudou sociologia, filosofia, economia e história na Freie Universität Berlin entre os anos 1963 e 1969, tornando-se ali professor titular de sociologia em 1980. Ganßmann foi um importante sociólogo da economia, tendo vivenciado e participado do florescimento das novas leituras e debates em torno do pensamento de Karl Marx que despontavam na Alemanha particularmente a partir de fins dos anos 1960. Foi coautor da obra coletiva, em dois volumes e influente na época, intitulada Krise und Kapitalismus bei Marx [Crise e capitalismo em Marx]. Além de ensaios e artigos, escreveu os livros: Geld und Arbeit [Dinheiro e trabalho] (1996), Politische Ökonomiedes Sozialstaats [Política econômica do Estado social] (2000) e Doing Money: Elementary Monetary Theory from a Sociological Standpoint [Fazendo dinheiro: teoria monetária elementar de um ponto de vista sociológico] (2009), todos sem tradução.

a Doutorando em Filosofia pelo Programa de Pós-Graduação de Filosofia da Universidade de São Paulo e bolsista FAPESP, a quem agradeço pelo auxílio à pesquisa durante a qual a presente tradução foi realizada. 
Um pouco de reflexão sobre o dinheiro, por assim dizer sob o limiar de Gladstone (mas não foi Gladstone!), mostra que economia e sociologia devem fracassar diante do problema da explicação do dinheiro se a maldição de von Wiese não puder ser superada. O dinheiro não pode ser explicado como "função social que se tornou substância" (Simmel, 1907, p. 159) de acordo com o esquema neoclássico de uma redução de todos os fenômenos econômicos a uma relação simples entre indivíduo e objetos (não-humanos). Nem tampouco parece promissor, se o dinheiro é “uma máquina” (MıLL, 1900, p. 11), dissolvê-lo sociologicamente em uma relação imediata, pura, entre sujeito e sujeito.

Portanto, o modo como o problema do dinheiro é abordado pode servir como teste. Até que ponto a maldição de von Wiese de fato pesa sobre a economia e a sociologia? Pode o tratamento de o dinheiro servir como escada para fora dos escaninhos das disciplinas especializadas? Ainda assim se poderia pensar - bem abstratamente - que a economia e a sociologia se reencontram em um novo paradigma da interação materialmente mediada, de modo que se abriria aos economistas a dimensão social do seu objeto, e, aos sociólogos, finalmente, a sua dimensão "coisal".

Embora os problemas dos economistas sejam realmente sérios demais para ficarem a cargo dos economistas ${ }^{2}$, eu pretendo, no que segue, considerar o problema do dinheiro exclusivamente da perspectiva da recente sociologia. Trata-se, nesse caso, não apenas, e nem principalmente, da maldição de von Wiese, ou seja, a questão básica da determinação do objeto da sociologia, e sim da maneira como o problema da dominação se oculta por trás do problema do dinheiro, da maneira como "a relação do dinheiro nada mais é do que a álgebra do sistema de exploração e estratificação" (O’NEILL, 1982, p. 114).

A minha tese principal é que a recente sociologia, com o enquadramento do problema do dinheiro em uma teoria dos meios, é incapaz de decifrar aquela álgebra, e que a maldição de von Wiese provoca essa incapacidade: entender o dinheiro como meio simbolicamente generalizado da comunicação significa torná-lo inofensivo. Este caráter inofensivo ocorre exatamente porque a objetividade do dinheiro é abstraída, a saber, é abstraída sua existência como coisa. Essa abstração ocorre, pelo menos implicitamente, quando o dinheiro é posto em um mesmo nível com os outros meios simbolicamente generalizados da comunicação,

2 Cf. Ganßmann (1979) para um exame da argumentação neoclássica sob o aspecto da repressão da dimensão social da ação econômica. 
os quais se caracterizam, todos, por sua não-objetividade, isto é, pelo fato de que eles existem apenas na execução corrente da ação.

Eu gostaria de proceder da seguinte maneira: em primeiro lugar, com base na teoria parsoniana, eu pretendo tentar esclarecer a abordagem e os conceitos fundamentais da teoria do dinheiro baseada na teoria dos meios: o que significa símbolo, generalização, meio, e assim por diante? De um lado, Parsons se apoia ainda fortemente em sua concepção do dinheiro, na tradição econômica; de outro lado, ele concebe os outros meios (de saída: poder, influência e vínculo de valores) ainda expressamente como análogos ao dinheiro (I). Essa analogia com o dinheiro tem sido criticada. Eu apresento essa crítica com base na tentativa de Habermas de restringir a abrangência do conceito de meio aos sistemas da economia e da política, de modo que apenas dinheiro e poder devem valer como meio, ao passo que as categorias de influência e vínculo de valores pertenceriam ao mundo da vida. Na tentativa de conceber igualmente dinheiro e poder como meios, como "linguagem especial", contrapondo-lhe o entendimento linguístico do mundo da vida como meio de comunicação que é tecnicizado naquele regime, também Habermas atenua o problema do dinheiro (II). Finalmente, Luhmann procurou remover completamente o conceito de meio da analogia do dinheiro, concebendo-o mais nitidamente à maneira da teoria da comunicação. Assim, e por meio da introdução do conceito de autopoiesis, Luhmann lança a base para uma teoria do dinheiro altamente desenvolvida - em comparação com a tradição sociológica -, que é explicitamente formulada contra um entendimento da economia a partir do trabalho (III). Nessa medida, a concepção do dinheiro desenvolvida por Luhmann serve para uma confrontação com a concepção de Marx, que pode ser considerada como a tentativa de compreender o dinheiro como coisificação [Versachlichung] das relações sociais condicionada pela forma social do trabalho. Como conclusão, eu gostaria de pelo menos esboçar tal confrontação (IV).

\section{PARSONS: ALL DOLLARS ARE 'CREATED FREE AND EQUAL'3}

Parsons desenvolveu o conceito de meio simbolicamente generalizado da interação, ou de comunicação, concebendo de saída o dinheiro como um tal meio para então tentar construir, em analogia com o dinheiro, outros meios. Ele seguiu assim o seu conceito geral de sistemas sociais, segundo o qual estes sistemas precisariam resolver quatro problemas funcionais a fim de garantir a conservação de sua existência: adaptação (adaptation), realização dos fins (goalattainment), inte-

3 Parsons, 1967, p. 317. 
gração (integration) e manutenção do padrão latente (latent pattern maintenance). Parsons amplia inicialmente o assim chamado esquema AGIL - no que interessa ao contexto aqui - de modo a fazer corresponder quatro problemas funcionais a quatro subsistemas sociais, que, em seu processamento, diferenciam-se do seguinte modo: a economia desempenha a adaptação da sociedade ao seu ambiente, o sistema político visa à realização das finalidades sociais, a integração é efetuada pelo direito e pelo controle social, o subsistema da manutenção de padrão latente é o lugar no qual os vínculos culturais e motivacionais são atados a valores sociais. A teoria dos meios complementa essa concepção da formação do sistema atribuindo um meio a um subsistema, meio este que forma e dirige tanto processos de troca intrassistêmicos como também intersistêmicos ${ }^{4}$. O modo de operação de tal meio é observável no dinheiro, que, naturalmente, é atribuído ao sistema econômico. Parsons constrói então, seguindo o seu esquematismo compulsivo de quatro campos $^{5}$, outros meios: poder para o sistema político, influência para o integrativo, vínculo de valores para o sistema "manutenção do padrão latente"6.

Essa extrapolação é facilitada por uma concepção específica do dinheiro, que é a que concepção que aqui interessa: o dinheiro é, para Parsons, "essencialmente um fenômeno ‘simbólico’ e, por isso [...], sua análise requer um quadro de referência mais próximo ao da linguística que da tecnologia” (PARsons, 1967, p. 345).

A possibilidade de igualar o dinheiro com os outros meios depende da propriedade simbólica do dinheiro; como o evidencia a referência à linguística, todos os meios devem ser entendidos em analogia com a formação simbólica na linguagem. Que Parsons entende por símbolo? Como ele chega ao termo peculiar "meio simbolicamente generalizado"?

Simbolização e generalização estão, para Parsons, estreitamente relacionadas, no que ele se orienta originalmente pelas teorias behavioristas da aprendizagem?

4 “Os processos primários de troca por meio dos quais esses subsistemas são integrados entre si operam por meios simbolicamente generalizados" (PARsons, 1967, p. 349).

5 No Parsons tardio, essa compulsão vai tão longe que ela também acomoda o querido Deus (sob o nome sistema télico) e as zonas erógenas na lousa de quatro campos segundo o esquema AGIL (PARsons, 1978, p. 382 e 414).

6 Não entrarei na construção dos demais meios de outros níveis sistêmicos (cf. PARsons, 1978, p. 392s).

7 “[...] mesmo a mais elementar orientação da ação em níveis animais envolve signos que são pelo menos o começo da simbolização. Ele é inerente ao conceito de expectativa que envolve algum tipo de "generalização" de particularidades de situação de estímulo imediatamente corrente. [...] No nível humano, o passo dado é da orientação-signo para a verdadeira simbolização. [...] Quaisquer que possam ser as origens e os processos de desenvolvimento dos sistemas simbólicos, é bem claro que o alto grau de elaboração de sistemas de ação humana não é possível sem sistemas simbólicos relativamente estáveis em que o sentido não é predominantemente dependente de situações altamente particularizadas. A implicação singularmente mais importante dessa generalização é talvez a possibilidade de comunicação, pois as situações de dois atores nunca 
Para Parsons, símbolos são signos elaborados no contexto da ação humana que - aqui reside a generalização - podem-se distinguir por meio da capacidade de seu uso independente das situações específicas. Pode-se discutir se símbolos nem sempre são "generalizados", se a generalização nem sempre está ligada à simbolização, se portanto a geração linguística parsoniana é pleonástica. Mas quem ficaria surpreso com Parsons? Simbolização e generalização valem como pressuposições da comunicação humana. Mais difícil de esclarecer é o que Parsons entende por meio. Ele assume que são necessárias determinadas coordenações entre os subsistemas, coordenações que são realizadas por meios, cuja capacidade mais importante é a de exceder as fronteiras dos sistemas a fim de efetuar "trocas" (cf. PARSONS, 1978, p. 394 ss). Mas a que propriedades dos meios essa capacidade está ligada, isso permanece obscuro.

Retornemos ao dinheiro. Que é generalizado no dinheiro e até que ponto ele é um meio? De acordo com Parsons, o dinheiro "é simbólico na medida em que, embora medindo e, assim, 'representando' o valor econômico ou a utilidade, ele mesmo não possui utilidade no sentido primário do consumo - ele não tem 'valor no uso', mas apenas 'na troca', ou seja, representando a posse de coisas que têm utilidade" (PARsons, 1967, p. 306). Que com o dinheiro ocorra generalização, isso é óbvio: o dinheiro funciona evidentemente, em grande medida, de maneira independente de situações particulares. (Poder-se-ia mesmo pensar em atribuir ao dinheiro um poder de definição sobre as situações. Com uma oferta de dinheiro suficientemente alta, praticamente tudo pode ser regulado). Toda a tradição econômica já sabia que o dinheiro é (pelo menos) um meio ${ }^{8}$.

Vejamos a questão: o dinheiro é, pois, um símbolo sobretudo porque ele mesmo não é útil, mas, por um lado, "mede e representa" utilidade (= valor), e, por outro lado, pode ser utilizado para a aquisição de coisas úteis. Deixando de lado o idiossincrático conceito (econômico) de valor, que fica ainda aquém da compreensão da escola da utilidade marginal ${ }^{9}$, é surpreendente que Parsons não queira fundamentar a propriedade simbólica do dinheiro exclusivamente por sua função de representação (dinheiro "representa" utilidade), mas também a partir de suas funções como medida do valor e meio de troca. É incontroverso que um

são idênticas e, sem a capacidade de abstrair o sentido da maioria das situações particulares, a comunicação seria impossível (PARsons, 1951, p. 10s).

8 Discordâncias surgem apenas quando se tem de perguntar o que é um meio: ele tem sem dúvida a função de mediar, mas como e entre o quê ou quem?

9 Que o valor não pode emanar imediatamente da utilidade, isso é um lugar-comum entre economistas, para além de suas diferenças sobre a teoria do valor. Uma teoria do valor baseada no conceito de utilidade pode operar apenas com o acoplamento de utilidade e escassez. 
símbolo representa "algo", por exemplo, a coroa de um rei representa uma relação de soberania. Mas é discutível, em primeiro lugar, se o dinheiro de fato é símbolo da utilidade; em segundo lugar, é discutível se um símbolo pode simultaneamente medir aquilo que ele simboliza; por fim, é discutível como pode um símbolo ser, ao mesmo tempo, meio de apropriação daquilo que ele simboliza.

Pelo menos as duas últimas funções podem diferenciar o dinheiro dos demais símbolos de tal modo que a aplicabilidade do conceito de símbolo se torna problemática. Na tese de que o dinheiro simbolizaria valor (na troca), e de que o valor seria imediatamente utilidade, é digno de nota que, com a simplesmente suposta vinculação dinheiro-valor-utilidade, é ignorado de antemão o fenômeno da "busca pura e simples de ganho de dinheiro" [nackten Geldgewinnstrebens] (Max Weber). Com isso se ignora que o uso do dinheiro na troca orientada à utilidade apenas abre o horizonte de ação do capitalista, mas não o limita. A cadeia de ação M-D-M (vender para comprar) é pressuposição para a sua inversão em D-M-D (comprar para vender). A inversão significa, e não apenas nisso Marx e Weber estão de acordo, que se trata de "busca desmedida de enriquecimento" (Marx), e não apenas de um prolongamento da série meio-fim inscrito desde sempre no motivo da satisfação de carências.

Com a afirmação de que o dinheiro seria um símbolo precisamente porque ele representa valor sem ele mesmo ser valor, Parsons se compromete com o caráter inofensivo do dinheiro ${ }^{10}$, que finalmente resulta no caráter inofensivo do motivo do lucro. Mas, com essa tese, ele tem também as costumeiras dificuldades: como o uso do dinheiro pode ser de todo plausível? Os bens têm seu valor por causa de sua utilidade. Mas o dinheiro, como símbolo, não é útil (em relação a carências subjetivamente individuais). Por que um homo economicus mais ou menos racional aceitaria, na troca, dinheiro em vez de bens? Parsons acha que a ausência de utilidade, que distingue o dinheiro, seria compensada em razão de que aquele que recebe o dinheiro obteria "quatro importantes graus de liberdade em sua participação na totalidade do sistema de troca": primeiro, ele é livre no que ele quer comprar; segundo, ele é livre na escolha daquele de quem ele quer comprar; terceiro, ele pode decidir quando ele compra; quarto, ele pode, por causa dessa possibilidade de escolha, também aceitar ou rejeitar as condições nas quais ele compra (cf. PARsons, 1967, p. 307).

Como é frequente no caso dessa argumentação, também em Parsons o verdadeiro problema é evitado: para aquele que aceita o dinheiro na troca, os

10 “’Dinheiro’ não é uma inofensiva “disposição sobre utilidades indefinidas” (WEBER, 1972, p. 58). 
denominados graus de liberdade existem apenas se ele pode estar suficientemente seguro de que um terceiro desconhecido aceitará igualmente dinheiro. A aceitação de um dinheiro sem utilidade e, por isso, sem valor não é explicada pela generalização da expectativa de aceitação, isto é, pela expectativa de que todos aceitarão o dinheiro porque cada um calcula que todos os demais igualmente o aceitarão. Isso não é uma explicação, mas antes um tipo de loucura coletiva ${ }^{11}$. Aquele que aceita o dinheiro pode tomar seu tempo, comportar-se segundo suas escolhas, etc., apenas se se pressupõe uma assimetria entre dinheiro e mercadorias que privilegia o dinheiro. É na fundamentação desse privilégio que repousa evidentemente uma dificuldade principal da teoria do dinheiro, que se torna ainda mais aguda quando, com Parsons, parte-se de que o dinheiro é apenas um símbolo de valor, não sendo ele mesmo, contudo, valor. Então as condições para a aceitação do dinheiro são ainda mais repletas de pressuposição do que no caso da assunção de uma equivalência entre mercadoria e dinheiro. Parsons menciona o problema da aceitação do dinheiro como o avesso do afirmado ganho de liberdade, esquecendo-se, porém, de que este ganho já tinha de compensar a falta de valor do dinheiro: "O outro lado do ganho de graus de liberdade é, naturalmente, o risco envolvido nas probabilidades da aceitação de dinheiro por outros e da estabilidade de seu valor" (ibid.). Mas de repente o dinheiro tem novamente valor? Já não é, pois, símbolo?

Não era bem isso que se pretendia. Pelo menos para as sociedades modernas, considera-se que elas utilizam dinheiro sem valor. A aceitação deste é explicado ${ }^{12}$, ao fim e ao cabo, pela referência à confiança no sistema monetário, provavelmente porque crédito vem de credere.

A doutrina parsoniana termina - sob aspectos sistemáticos - com a referência à confiança como pressuposição para a capacidade funcional do símbolo monetário (cf. PARsons, 1967, p. 313). Além da adoção de determinações funcionais a partir da tradição econômica (medida de valor, meio de troca), essa doutrina consiste, antes, de uma lista de desideratos para o dinheiro, e não de explicações de como se chega à formação do dinheiro como símbolo, de como ele é institucionalizado, de como é estabelecida a confiança no sistema monetário. A referência de Parsons à linguística acima citada sugere que ele, tudo somado, está pensando em uma analogia com a linguagem (como mais tarde expressamente Habermas e Luhmann) para uma explicação desse tipo. Contudo, é discutível se a formação do dinheiro

11 Em Döblin (1984, p. 316), é precisamente essa a explicação dada por um deus babilônico condenado a viver na Terra em tempos modernos.

12 A “aceitação desse dinheiro 'sem valor' assenta sobre uma determinada confiança institucionalizada no sistema monetário” (PARSONS, 1967). 
como meio simbolicamente generalizado pode ser entendida de maneira similar à formação de palavras como signos linguísticos a partir de esquemas de ação significativa ${ }^{13}$, sendo sua objetivação por escrito e assim por diante. Todos pensam em tais analogias, mas alguns se sentem desconfortáveis ao fazê-lo. Habermas se voltou contra a suposição "de que meios de controle arbitrários [Steuerungs medien] poderiam se diferenciar da linguagem", pois "a própria estrutura da linguagem" submete "esse processo a restrições" (HABERMAS, 1981, p. 391).

\section{HABERMAS: DINHEIRO VS. MUNDO DA VIDA}

Mas Habermas, em sua discussão com a teoria parsoniana dos meios ${ }^{14}$, não vai tão longe a ponto de criticar sua analogia linguística. Antes, ele procura assumir o conceito de meio e, ao mesmo tempo, circunscrever sua abrangência ao dinheiro e ao poder. Dinheiro e poder representam, como meios, na economia e na política, formações de subsistema sociais que, segundo Habermas, produzem consequências sociais patológicas por meio de sua expansão aos contextos (originais) do mundo da vida. O processo real - para Habermas - da "colonização do mundo da vida" se repete na teoria: Habermas acusa Parsons e a teoria do sistema como um todo de um imperialismo que dissimula a diferença entre integração social e integração sistêmica, reduzindo a "intersubjetividade [...] aos mecanismos de troca e de organização" (HABERMAS, 1981, p. 384). A teoria do sistema invadiria, injustificadamente, "a área interna da teoria da ação comunicativa" (ibid.). Para Habermas, o mais perturbador é que "Parsons [...] quer reconduzir a atividade de integração [Integrationsleistung] da própria comunicação linguística aos mecanismos de troca" (ibid.). Com respeito à relação entre linguagem e dinheiro, a objeção não é que Parsons pensa o dinheiro em analogia com a linguagem, mas que ele pensa a linguagem em analogia com o dinheiro. Para nosso tema, o interessante na reencenação, por Habermas, do drama pastoril [Schäferspiel] "comunidade versus sociedade" - terminologicamente enriquecida por quase 100 anos de história da sociologia - está em saber de que forma ele implementa e modifica, em sua apresentação do mundo da vida, a teoria parsoniana dos meios e, especialmente, do dinheiro. Em princípio, ele aceita pelo valor de face o desiderato funcional de Parsons acerca do meio monetário a fim de dramatizar de maneira pujante o conflito entre o Don Quixote do mundo da vida e os moinhos de vento do sistema: o dinheiro deve garantir que os moinhos de vento girem com uma inexorabilidade

13 Cf., por exemplo, Kamlah (1967, p. 434) para o esclarecimento da conexão entre esquemas de ação, signos e linguagem.

14 Para o que segue, cf. Habermas (1980) e, em adoção literal, (1981, v.2, p. 384-419). 
sem atritos, o que só pode aumentar nossa compaixão por nosso pobre cavaleiro. Ao mesmo tempo, Habermas quer restringir a abrangência do conceito de meio pela via da comprovação "de que somente os domínios funcionais da reprodução material podem ser diferenciados do mundo da vida por meios de controle" (HABERMAS, 1981, p. 391). Ao contrário disso, deve-se considerar "que o entendimento, como mecanismo de coordenação da ação nos domínios da vida que cumprem principalmente funções da reprodução cultural, da integração social e da socialização, embora ampliado por tecnologias da comunicação, organizacionalmente mediado e racionalizado, não pode ser substituído por meios e, com isso, ser tecnicizado" (HABERMAS, 1981, p. 400).

Habermas dificulta essa dupla comprovação antes de tudo porque ele adota as pressuposições de Parsons: "A troca entre sistemas e seu ambiente, e a troca entre unidades funcionalmente específicas dentro de um sistema, têm de se realizar por meio de alguns meios" (HABERMAs, 1981, p. 388). Isso parece ser um tipo de lei natural, em consequência da qual também se "evidencia que, para sistemas de ação, a comunicação linguística apresenta um tal meio, do qual linguagens especiais como dinheiro e poder emprestam sua estrutura (ibid.). Uma vez aceita a separação, realizada por Habermas, entre sistema e mundo da vida, seria mais fácil para seus propósitos reservar a linguagem (e não a comunicação linguística), como "meio", ao mundo da vida, alcançando um contraste mais nítido com o dinheiro ao não interpretá-lo como "linguagem especial”. Por um lado, considera-se que o "dinheiro como meio [...] substitui a comunicação linguística em determinadas situações e sob determinados aspectos; essa substituição reduz tanto o dispêndio de atividade interpretativa como também o risco de um fracasso do entendimento" (HABERMAS, 1981, p. 391 ss). Por outro lado, a linguagem também serve de modelo aos meios sob outros aspectos. Algumas características, por exemplo, a incorporação simbólica de conteúdos semânticos ou a estrutura de demanda e satisfação, imitam os meios de coordenação" (HABERMAs, 1981, p. 392 ss). De qualquer modo, os "meios de coordenação não podem ser entendidos como uma especificação funcional da linguagem" (ibid.), pois a "reconversão da coordenação da ação pela linguagem e (quer dizer: 'em' H.G.) pelos meios de coordenação significa desacoplar completamente a interação de seus contextos que são o mundo da vida” (HABERMAS, 1981, p. 394). Portanto, o dinheiro é uma "linguagem especial", mas nenhuma "especificação funcional da linguagem"? Tais pobrezas conceituais têm de suceder quando se reifica a separação entre sistema e mundo da vida e, não obstante, aferra-se à linguistificação do dinheiro. 
Seja como for, chegamos ao conteúdo do conceito habermasiano de dinheiro. Habermas procura em todo caso preencher a analogia linguística no sentido de Parsons. Portanto, o dinheiro tem "as propriedades de um código, com cujo auxílio informações podem ser transmitidas do emissor para o receptor" (HABERMAS, 1981).

À primeira vista, o recurso à terminologia “código-mensagem”, “emissor-receptor” é bastante plausível. Em uma definição mínima, um código pode ser entendido como um conjunto de restrições e um conjunto de regras de acordo com os quais "mensagens" podem ser construídas. Esquematicamente, pode-se apresentar um sistema de comunicação simples da seguinte maneira (cf. WILDEN, 1980, p. 496):

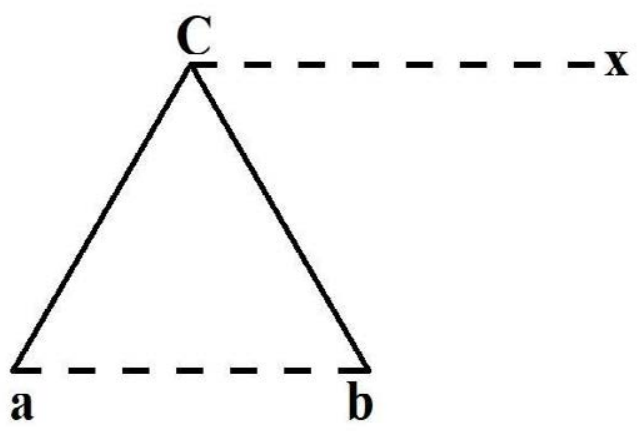

$\mathbf{C}$ - locus do código

$\mathbf{a}, \mathbf{b}$ - emissor-receptor mediado pelo código

a-b - canal-“mensagem"

$\mathbf{C - a}, \mathbf{C}-\mathbf{b}$ - canais de codificação

$\mathbf{x}$ - referência ao ambiente

$C$ seria o dinheiro, $C$ - $a$ e $C$ - $b$ significam que $a$ e $b$ expressam suas mensagens um ao outro $(a-b)$. Aquilo que eles expressam dessa maneira está inteiramente em aberto (por exemplo, "dê-me uma contenção de impostos, então eu lhe dou 5 marcos e 50 centavos"), pertencendo ao ambiente como referência do sistema de comunicação (referência a carências, condições de produção, propriedades pessoais, etc.,). O modelo simples de código-mensagem é obviamente subcomplexo diante do curso fático no uso do dinheiro. No melhor dos casos, ele pode ilustrar o aspecto do entendimento entre comprador e vendedor (algo como o regateio, a menos que não inclua referência ao número de filhos do vendedor), mas não a compra e venda real. Este último fato concerne não apenas à referência a um código, mas à troca efetiva da propriedade entre mercadorias e (signos de) dinheiro.

De acordo com Habermas, o “meio monetário” permite

a criação e a mediação de expressões simbólicas com estrutura de preferências embutida. Elas podem informar o receptor de uma oferta e motivá-lo a aceitar a oferta. No entanto, visto que essa aceitação não pode se basear na declaração afirmativa sobre uma demanda de validade criticável, devendo, antes, transcorrer de acordo com um automatismo independente de processos de formação de 
consenso, o código-meio só é válido para uma classe bem limitada de situações padrão. (HABERMAS, 1981, p. 395)

Essa argumentação sofre visivelmente com o fato de que Habermas procura estabelecer uma diferença entre o entendimento puramente linguístico e o entendimento mediado pelo dinheiro, diferença que não existe dessa forma. Antes de mais nada: que são - além de monstros linguísticos [Sprachungeheuern] - "expressões simbólicas com estrutura de preferências embutida"? O que provavelmente se quer dizer com isso é que, para quem paga, menos dinheiro é melhor do que mais dinheiro, sendo o inverso para quem recebe o pagamento. Mas por que a oferta e a aceitação de um pagamento em dinheiro devem transcorrer de acordo com um "automatismo independente de processos de formação de consenso"? É certo que dificilmente ocorreria a alguém regatear o preço do pão de manhã. Mas é este tipo de atividade de desencargo comunicacional realmente uma atividade importante e específica do código do dinheiro e que requer explicação? Que a entrega de alguns pedaços de papel dispendiosamente impressos pode induzir a mudança de propriedade de quase tudo o que se possa imaginar, não é este o fenômeno que realmente requer explicação? E não requer explicação o fato de que, com a mudança de propriedade, não se trata apenas de títulos, mas de uso e consumo reais?

Esse aspecto do "código-meio" (que é algo similar a um visor de telecomunicação) não interessa a Habermas. O que o interessa é a sua demarcação em relação à linguagem. Desse modo, o dinheiro pode ser empregado apenas em situações padrão de troca de bens em que agentes da troca perseguem interesses econômicos, agentes estes que se orientam por considerações de utilidade e por uma "atitude objetivante” em relação à sua situação (cf. HABERMAs, 1981. P. 395ss). Portanto, de imediato, padres já não poderiam passar o cesto do dízimo e a prostituição seria também proibida, a menos que os participantes pudessem apresentar um cálculo de otimização com referência à utilidade como "valor generalizado".

Tais exemplos de situações - multiplicáveis à vontade - nas quais o "código do dinheiro" é empregado mostram que, em seu campo de aplicação, ele de modo algum é limitado como Habermas supõe. Considere-se isso bom ou mau, simplesmente não há relação social que seja resistente à subsunção a esse código. Com isso eu não quero afirmar que essa subsunção poderia não ter consequências patológicas - algo que Habermas enfatiza. Antes, trata-se de saber a razão por 
que ele quer utilizar a categoria "guarda-chuva" de utilidade ${ }^{15} \mathrm{e}$, simultaneamente, interpretá-la de modo restritivo: deve haver âmbitos sociais ("situações padrão") para as quais a orientação à utilidade é determinante como "valor" generalizado, havendo outras para as quais tal orientação não pode substituir o entendimento linguístico. Diante disso, parece mais auspicioso justificar a limitação do cálculo de utilidade de maneira diferente, tal como, por exemplo, o tipo de crítica do utilitarismo do primeiro Parsons (1937), isto é, tentando mostrar que mesmo a ação mais racionalmente orientada a fins, a mais instrumental, não pode ser pensada sem referências normativas. Desse modo se estaria protegido contra uma reificação de distinções analíticas como aquela em que Habermas incorre ao empregar as categorias de sistema e mundo da vida: sistema e mundo da vida não são âmbitos sociais separados. As categorias designam, antes, distintos acessos à análise de situações de ação, distintas perspectivas teóricas que são orientadas a um e o mesmo "objeto real". O fato de o cesto do dízimo se encher aos domingos não pode ser explicado, do ponto de vista dos participantes, sem referência ao seu contexto no mundo da vida, ao passo que, em perspectiva sistêmica, pode interessar o modo como disposições religiosas são vinculadas com a atualização do "código do dinheiro". A tentativa de Habermas de circunscrever, normativamente, o âmbito de validade do "código do dinheiro" com referência ao conceito de utilidade é interessante ainda em outro aspecto: por meio dessa referência, assim como se dá com Parsons, o dinheiro é tornado inofensivo. O fenômeno da "busca pura e simples de ganho de dinheiro”, já não ligada a considerações de utilidade, não é categorialmente levado a sério por Habermas, quando ele afirma que o uso de dinheiro implica uma orientação à utilidade como "valor generalizado". Portanto, se já não há enriquecimento pelo enriquecimento - vinculado à instituição do dinheiro -, a dinâmica do ímpeto capitalista da ação desaparece do palco mundial habermasiano. A doutrina neoclássica e vulgar da soberania do consumidor fica à espera como última palavra sobre o específico da "moderna" economia.

Finalmente, abordemos ainda um outro aspecto da doutrina habermasiana do dinheiro. Como Parsons - e Luhmann (cf. 1983, p. 154) -, Habermas atribui grande valor à constatação de que o dinheiro não tem valor: "o dinheiro não é uma mercadoria nem um fator de produção, ele simboliza quantidades de valor, mas, como meio, nenhum valor é intrínseco a ele mesmo" (HABERMAS, 1981, p. 397). De maneira puramente descritiva, na medida em que nos relacionamos com os sinais

15 Na visão neoclássica, forjada pela inabalada tradição utilitarista, o “código"- utilidade é universalmente aplicável a todas as situações de ação. 
de dinheiro tal como circulam ordinariamente nas sociedades modernas, isso é correto. Entretanto, tal concepção do dinheiro não funciona.

Na esteira de sua crítica à "super-generalização" parsoniana do conceito de meio, o próprio Habermas aponta que o meio precisa ser constituído de tal modo "que ele possa ser medido, estocado, alienado em certas ordens de grandeza" (HABERMAS, 1981, p. 396). Meios precisam poder circular e incorporar quantidades mensuráveis de valor às quais todos os participantes podem se referir, independentemente dos contextos, como uma grandeza objetiva" (HABERMAS, 1981, p. 397). Com a elucidação dessas propriedades, Habermas prepara o argumento de que "influência" e "vínculo de valores", construídos por Parsons como meios, não seriam de fato meios, pois eles não teriam aquelas propriedades ${ }^{16}$.

Mas deixemos esse contexto de lado. Em referência à sua constatação de que o dinheiro não teria valor, e sim "incorpora simbolicamente quantidades de valor" que são medidas e postas em circulação, Habermas teria de poder colocar a questão sobre como isso é possível. Aqui, evidentemente, a analogia linguística já não basta. Decerto se pode dizer que proferimentos linguísticos encontram “incorporação simbólica” por meio da escrita. E já a linguagem popular sabe que o "que tens preto sobre branco, pra casa levarás tranquilo"17. Mas algo é "medido" por meio da codificação secundária da linguagem na escrita? Ou então o conteúdo semântico dos proferimentos linguísticos é mesmo perdido por meio do registro unidimensional na escrita? E será que ocorreria a alguém a ideia de trocar o significado de um proferimento linguístico por seu registro tal como um número impresso em uma cédula de papel?

Em resumo, no uso do dinheiro acontece algo que não ocorre no entendimento por meio da linguagem. A analogia linguística não vai muito longe, pois com sua ajuda não se podem esclarecer as propriedades excedentes do "meio" monetário, isto é, propriedades que excedem aquelas do "meio" da linguagem. Elas nem sequer são percebidas em sua plena relevância social: a disposição de dinheiro decide sobre a participação ou a exclusão da riqueza social. A disposição de dinheiro depende do cumprimento de determinadas condições: quem não tem nenhum dinheiro precisa trabalhar ou se tornar criminoso. Em contraste, não se pode ser

16 Eu considero essa crítica inteiramente justificada. Contudo, Habermas é inconsequente quando ele se detém ante o liminar, além do qual ele também teria de rejeitar o conceito de "poder" como meio (cf. HABERMAS, 1981, p. 403). É “irremediavelmente metafórico" atribuir "mensurabilidade, capacidade de circulação e capacidade de ser depositado" ao poder.

17 N.T.: A referência ao dito se acha em Goethe, J. W. Fausto: uma tragédia (primeira parte). $6^{\mathrm{a}}$ ed. Trad: Jenny K. Segall. São Paulo: Editora 34, p. 191. Reproduzimos acima a tradução mencionada. 
excluído dessa maneira da participação na riqueza semântica da linguagem, isto é, tal participação não depende do cumprimento de condições impostas.

A palavra-chave "trabalhar" foi eliminada. Minha suposição- obviamente baseada em um contato muito próximo com as ideias de Marx - é que $a$ ) a insustentabilidade da analogia linguagem-dinheiro se liga ao fato de que o dinheiro (como sempre simbolicamente "diluído") é uma coisa, que b) o significado dessa propriedade coisal pode ser melhor explicada no contexto do trabalho e da produção da riqueza social do que no contexto da linguagem e da coordenação da ação. A discussão da doutrina do dinheiro de Luhmann reforçará essa suposição.

\section{LUHMANN: PAGAMENTO POR AUTOPOIESIS}

Em seus trabalhos mais recentes sobre dinheiro e de sociologia econômica, Luhmann se desprendeu mais do que Habermas da proposta parsoniana, tanto no que diz respeito ao conceito de meio como também à teoria do sistema. Desde cedo Luhmann havia tentado se libertar da analogia do dinheiro (cf. LuHmann, 1972, p. 196 ss). Agora, a teoria do sistema, vista por Parsons na clara orientação input-output, é reconvertida no conceito de autopoiesis:

Sistemas autopoiéticos são sistemas fechados na medida em que eles não podem extrair de seu ambiente aquilo que eles aplicam como unidade para sua própria reprodução (portanto, seus elementos, seus processos, eles mesmos). Não obstante, eles são sistemas abertos na medida em que podem realizar essa autorreprodução apenas em um ambiente e em diferença com um ambiente. (LuHMANN, 1984, p. 311) ${ }^{18}$

Em contraste com a representação input-output conforme a relação entre sistema e ambiente, em que o intercâmbio transfronteiriço, por assim dizer, é tematizado (e os meios têm uma função, se não a mais importante, na mediação de "boundary interchanges"), Luhmann coloca o centro de sua análise sistêmica no aspecto do caráter fechado autorreferencial. Essa concepção da produção sistêmica, implausível se considerada em si mesma (GANßMANN, 1986), sustenta-se em que Luhmann concebe os sistemas sociais puramente como sistemas de comunicação.

18 Aqui Luhmann, expressamente, não formula o processo de reprodução de modo tal que se trataria de uma contraprestação do sistema que constrói seus elementos para si a partir de um material previamente encontrado no ambiente (como uma lagarta comendo folhas), mas sim de modo tal que os elementos não podem ser "extraídos" do ambiente. A oclusão se transforma em um tipo de autarquia. 
Em relação à economia, isso significa: "Nem os recursos concernidos nem os estados psíquicos das pessoas participantes são elementos ou componentes do sistema [...]. A formação do sistema [...] situa-se exclusivamente no nível da própria ocorrência comunicativa" (LuHMANN, 1983, p. 153). A consequência imediata dessa conceituação é que a economia e a atividade econômica não são mais igualadas com cursos específicos de ação que de algum modo efetuam a reprodução material de uma sociedade. Luhmann só pode alcançar uma demarcação da economia como subsistema da sociedade interpretando um tema específico da comunicação que é suficientemente duradouro e problemático para apoiar a autodiferenciação de um subsistema. Aqui vem à tona também com Luhmann a recorrência neoclássica, o axioma da escassez: deve-se chegar a um "entendimento sobre o acesso a bens escassos" (LuHMANn, 1983, p. 154) ${ }^{19}$. Em contraste com o naturalismo e com o "esquecimento do dinheiro" (Backhaus) ${ }^{20}$ pela economia neoclássica, Luhmann procura, porém, complementar o axioma da escassez em dois aspectos. Ele não considera a escassez como pressuposição natural da existência humana, mas que o problema social do atual sofrimento por escassez causado por outros [...] é o problema de referência da economia" (Luhmann, 1984, p. 317) - em outras palavras, a escassez surge no contexto social ${ }^{21}$. Além disso, Luhmann vincula desde logo a escassez como tema da comunicação no sistema da economia com uma forma determinada da comunicação, aquela do dinheiro: "A autodiferenciação de um sistema funcional especial [...] é, contudo, posta em operação apenas por meio do dinheiro como meio de comunicação, e precisamente pela ocorrência de que, com o auxílio do dinheiro, pode-se sistematizar um determinado tipo de ação comunicativa, a saber, o pagamento" (Luhmann, 1983, p. 154).

Com o estabelecimento do código monetário - como quer que possa ter vindo a ocorrer - , a economia pode ser caracterizada agora como um sistema de comunicação no qual há duas "linguagens de escassez: as linguagens dos bens e a do dinheiro" (LuHmann, 1984, p. 310). Ambas as linguagens se entrelaçam quando

19 Aqui Luhmann salta por cima do ponto de partida do proeminente "problema hobbesiano da ordem" em Parsons: por que alguém não pode simplesmente tomar os bens quando eles são escassos?

20 N.T.: Referência a Hans-Georg Backhaus, autor que, tendo sido aluno de Theodor W. Adorno nos anos 1960, foi um dos pioneiros, juntamente com Helmut Reichelt e outros, da chamada Nova leitura de Marx (Neue Marx-Lektüre), desenvolvida a partir de meados dos anos 1960. Entre suas principais contribuições está a reconstrução da teoria do valor de Marx como uma teoria monetária do valor.

21 A escassez parece mesmo ser socialmente constitutiva: "Sociedade significa que seres humanos não operam sozinhos e independentemente uns dos outros na determinação e satisfação daquilo que eles experimentam como carências. Cada um estimula e perturba os outros. É a partir disso, e não da inconfiabilidade da natureza, que se produz uma carência de predisposição" (LuHMANN, 1984, p. 317). 
se paga por "desempenhos". "A estrutura da economia consiste na coordenação desses contextos operativos. Pode-se reduzir a escassez de mercadorias apenas acrescentando-lhe uma segunda escassez, uma escassez de reserva, por assim dizer" (ibid.).

Em outras palavras, o acesso a bens escassos para os participantes no sistema econômico é possível porque eles depositam uma soma de dinheiro no lugar vazio deixado pelo pagamento dos preços dos bens, soma esta que é igualmente parte de uma quantidade agregada escassa, com o que se alcança, portanto, como que artificialmente (ou pelo Estado), a "duplicação de escassez". Por conseguinte, para o sistema de comunicação com "duas linguagens de escassez", aplica-se o seguinte: "o 'unitact' da economia é o pagamento" (Luhmann, 1984, p. 312), pois o pagamento é feito por algo que é escasso e com algo que é escasso.

Com a concentração no "pagamento", Luhmann tem imediatamente mais vantagens em comparação com a doutrina do dinheiro em Parsons e Habermas.

Em primeiro lugar, a analogia "código-mensagem", que Luhmann também utiliza, é mais perceptiva: a "mensagem" de pagamento corresponde ao "código" de dinheiro. Com isso, Luhmann consegue isolar, sem entrar na "referência externa" dos pagamentos (ou seja, as questões: quem é pago e pelo quê), um tipo de ação como especificamente econômica: sempre que o dinheiro é utilizado, que é pago, a atividade é econômica. Luhmann, portanto, não precisa se esforçar na busca por "situações padrão" (em última instância, normativamente determinadas) às quais o código-dinheiro deve ser relacionado exclusivamente.

Em segundo lugar, Luhmann consegue lidar com o problema da perda de informação que ocorre com a operação do código monetário em virtude de sua unidimensionalidade ${ }^{22}$. O código do dinheiro retrata de modo unidimensional um universo multidimensional de mercadorias e atividades. Pergunta-se, pois, como a perda de informação em questão pode ser funcional, como o sistema econômico pode ser funcional apenas mediante a "linguagem dos preços" (Luhmann, 1983, p. 165). Luhmann obtém aqui uma perspectiva de crítica da economia na qual ele pode tematizar a cegueira do sistema econômico contra as sobrecargas ambientais produzidas por ele mesmo: apenas aquilo que pode ser expresso na "linguagem dos preços” é retratado no monitor do sistema (cf. especialmente LuHMANN, 1983, p.

22 Parsons (1951, p. 124) havia notado o fenômeno, mas não o esclareceu. "Poder econômico, particularmente definido de modo cultural e configurado pela institucionalização do dinheiro, tem propriedades singulares que não são compartilhadas por nenhum outro fenômeno de todo o sistema da interação social. A mais interessante dessas propriedades [...] é o fato de que ela pode [...] ser tratada como um elemento linearmente quantitativo ou variável no equilíbrio total de sistemas sociais". 
167 ss). Em terceiro lugar - em contraste com Parsons e Habermas -, o fenômeno da "busca pura e simples de ganho de dinheiro" se encaixa bem na concepção luhmanniana, impondo-se mesmo diretamente quando pagamentos são considerados como elementos autopoiéticos. "Pagamentos têm todas as propriedades de um elemento autopoiético: eles são possíveis apenas em razão de pagamentos e não têm nenhum outro sentido (!), no contexto recursivo da autopoiesis da economia, senão o de possibilitar pagamentos" (Luhmann, 1984, p. 312). Somente quando há um curso de ação típico que assume reflexivamente esse sentido sistêmico de pagamentos por pagamentos, de modo "que, indiretamente, também mesmo aquele que paga obtém possibilidades de pagamento" (LuHMANn, 1984, p. 314), ou seja, de fazer lucro, somente assim se movem os agentes em um nível adequado ao sistema.

Em quarto lugar, finalmente, encontra-se em Luhmann pelo menos a suspeita da função excludente do dinheiro, isto é, de que apenas a disposição de dinheiro abre a possibilidade de acesso à riqueza social: "preços suspendem a compra" (Luhmann, 1983, p. 157). Contudo, como ela faz isso não é explicado.

Poder-se-ia estabelecer uma conexão desta função dos preços, a de que eles excluem o acesso à riqueza, com as atividades de ordenação de pagamentos: um sistema econômico autodiferenciado pelo meio comunicacional do dinheiro "ordena" de fato, a partir dos pagamentos [...], também comportamentos que não efetuam pagamentos, por exemplo, o trabalho" (Luhmann, 1983, p. 154). Aqui apenas uma fina camada ainda nos separa da compreensão trivial, mas omitida com elegante comedimento, a saber: quem não pode pagar precisa arranjar dinheiro; quem quer arranjar dinheiro precisa trabalhar para alguém que tem dinheiro ${ }^{23}$. Essa fina camada, sob a qual o dinheiro - especialmente em sua forma como capital - seria reconhecível como meio de dominação, é penetrada por Luhmann tão pouco quanto por Parsons e Habermas.

Perguntemo-nos porque isso acontece. Eu penso que a cegueira da nova doutrina sociológica do dinheiro diante da função do dinheiro como meio de dominação tem a ver com uma peculiar concepção de seu objeto - que lembra a maldição de von Wiese -, tendo esta concepção a ver, por seu turno, com uma perspectiva específica na qual o social em geral é pensado. A perspectiva pode ser melhor ilustrada ao se recorrer à representação de Parsons de uma hierarquia de comando cibernética (a). Polemicamente, eu pretendo caracterizar tal concepção

23 Eu me abstenho da opção alternativa da criminalidade, cada vez mais preferida de maneira manifesta por aqueles que entendem algo sobre dinheiro. A propósito, é esta também a opção dos deuses de Döblin que foram banidos da Terra diante da imposição de trabalhar por dinheiro. 
peculiar da seguinte maneira: nas teorias sociológicas aqui examinadas, o termo "agir" significa uma metáfora para "falar" $(b)^{24}$.

a) Em seus trabalhos dos anos 60 e 70, Parsons dissolveu a simetria das quatro funções sistêmicas do esquema AGIL por meio da introdução da ideia de uma hierarquia cibernética de comando ou de controle. Tal ideia se baseia na afirmação de que sistemas que utilizam muita informação e pouca energia controlam aqueles sistemas que utilizam pouca informação e muita energia (como, por exemplo, o sistema de controle eletrônico de uma máquina de lavar que controla o fluxo de água, o abastecimento de energia, o motor, etc.). O esquema AGIL se transforma assim no esquema LIGA, o que significa, com respeito aos subsistemas sociais primários: o sistema de “manutenção do padrão" (L), no qual valores culturais são atualizados, controla o sistema de integração (I), este, por sua vez, controla o político (G), e o sistema político controla a economia (A). Em sentido oposto à hierarquia de controle, há uma hierarquia de “conditions", que é pensada em conexão com a doutrina da emergência, de tal modo que os sistemas de alta carga informacional repousam, de modo evolucionário, sobre sistemas de alta carga energética como suas pressuposições necessárias, mas não suficientes (cf. PArsons, 1966, p. 28ss).

A hierarquia de controle cibernético funciona agora, segundo Parsons, de tal maneira que, ao nos movermos para baixo, o controle de cada vez mais condições necessárias permite a implementação de padrões, planos e programas" (ibid.).

Agora essa ideia de controle cibernético pode, como o próprio esquema de quatro funções, ser aplicada em todos os níveis sistêmicos e vinculada com um programa explicativo, podendo ser resumida na breve fórmula: se eu conheço o modus operandi do controle, então eu também sei suficientemente o que ocorre no nível dos sistemas (ou unidades, elementos) controlados. Portanto, a perspectiva de explicação é "de cima” para "baixo". Aplicada à teoria dos meios, na medida em que estes são pensados como códigos de controle, isso significa o seguinte: se eu conheço o modus operandi daquele código, então eu sei suficientemente o que se passa no subsistema controlado.

24 Na inversão do título de um ensaio de Jürgen Frese (1967): a fala como metáfora para a ação. Pode-se jogar aqui a etimologia de "Hand-eln": não se tratar de uma questão prática, e sim de uma“Kopf-eln" [uma questão de significações]. N.T.: O autor faz um jogo etimológico com os termos no alemão. De um lado, Handeln (ação) como verbo nominalizado de handeln (agir), que contém o substantivo Hand (mão); de outro, a construção Kopf-eln, que contém o substantivo $K o p f$ (cabeça) e remete ainda ao verbo köpfeln, utilizado em certas regiões com o sentido tanto de "mergulhar" (numa piscina, por exemplo) como de "cabecear" (como em uma partida de futebol), podendo conotar de modo geral algo como um entrar de cabeça. A intenção é realçar o contraste entre uma ação objetivamente prática e uma ação que se dá essencialmente por significações. 
b) Deixemos Parsons e retornemos a Luhmann e ao problema do dinheiro. Tendo em mente a ideia de uma hierarquia de controle cibernética, torna-se compreensível por que Luhmann procura identificar o código-dinheiro como constitutivo para o sistema econômico, dessa forma identificando a teoria do dinheiro como central para seu entendimento. Luhmann certamente não concebe seu conceito de meio de tal modo que estes pudessem contar diretamente como códigos de controle. Eles devem, antes, transpor o problema da improbabilidade da comunicação por meio da motivação da continuidade comunicacional. Mas o sistema econômico "ordena", como diz Luhmann (1983, p. 154), "a partir dos pagamentos, também comportamentos que não efetuam pagamentos, por exemplo, o trabalho, transferência de bens, uso exclusivo da propriedade, etc.”. Portanto, o uso de dinheiro pode ser entendido inteiramente no sentido do modo de operação de um código de controle. Como descrição, isso não é de modo algum falso.

Apesar disso, a teoria de Luhmann tem aí o seu ponto fraco. Como uma teoria que tem seu objeto puramente na comunicação ${ }^{25}$, ela já não consegue explicar aquele tipo de "atividades de ordenação" que vão além do evento comunicativo, da linguagem, até chegar à ação. Tal explicação exigiria que se pode pelo menos indicar as regras de tradução em virtude das quais sistemas de comunicação podem trazer outros sistemas para seu ambiente, fazendo com que estes sigam os objetivos definidos na comunicação. As atividades dos seres humanos não se esgotam na comunicação. Pois as pessoas comem, dormem, amam, trabalham, morrem e assim por diante. Luhmann sabe disso ${ }^{26}$. Mas que ele pretende ser capaz de apreender de maneira suficiente todas essas atividades por sua "codificação secundária” na comunicação, isso aponta para a convicção de que todas elas seriam controladas pela comunicação, de que elas seriam controláveis. Não se deve comungar dessa convicção. Caso contrário, não haveria como escapar da maldição de von Wiese.

\section{CONCLUSÃO}

Concluindo - primeiro com Luhmann. Um aspecto, até aqui não mencionado, da doutrina luhmanniana do dinheiro é que ela se vincula com uma "acompanhante

25 "Sociedade é um sistema autopoiético na base de uma comunicação significativa. Ela consiste de comunicações, ela consiste apenas de comunicações, ela consiste de todas as comunicações. Ela reproduz comunicação por meio de comunicação" (LuHmanN, 1984, p. 311).

26 Embora ele por vezes ignore o problema da tradução da comunicação em ação: "O sistema econômico, na demanda de uso de recursos, orienta-se [...] exclusivamente pela linguagem própria dos preços [...]. Uma comunicação sistematizada [...] desse modo destrói, como se sabe, recursos não reprodutíveis, e o faz muito rapidamente" (Luhmann, 1983, p. 167). Como uma comunicação pode destruir recursos? ("A última gota de óleo", idem). Plataformas de perfuração, oleodutos, seres humanos que os operam não fazem parte disso? 
referência alheia" ao marxismo. Ele polemiza com a posição central da categoria de "trabalho" na economia política clássica e na "teoria do materialismo dialético", que conduz, sedutoramente, "para expectativas de síntese e para esforços correspondentes sem que a função do dinheiro tivesse sido suficientemente esclarecida no contexto de economia e sociedade" (Luhmann, 1984, p. 309). Em contraposição, as reflexões de Luhmann visam a "substituir o fator trabalho [...] pelo conceito de codificação da comunicação" (LuhmanN, 1984, p. 310). A economia moderna teria de ser compreendida a partir do dinheiro, ao passo que o trabalho poderia "ser considerado apenas como colaboração na produção (orientada monetariamente) de mercadorias" (LuHmann, 1984, p. 309).

Essa polêmica é muito imprecisa. Qualquer que seja a avaliação que se faça da teoria monetária de Marx - há problemas nela -, Luhmann teria pelo menos de ter dado crédito a Marx por ter tentado esclarecer "a função do dinheiro no contexto de economia e sociedade”. A verdadeira acusação de Luhmann teria de ser que Marx empreendeu essa tentativa a partir do trabalho. Pois, mediado pelo conceito de valor, Marx queria mostrar que o dinheiro é uma expressão específica da forma social do trabalho no capitalismo. O dinheiro é derivado da forma-mercadoria dos produtos do trabalho, é mesmo mercadoria em primeiro lugar, ainda que uma mercadoria especial, na medida em que esta serve como equivalente universal para que outras mercadorias apresentem nela os seus valores.

Essa concepção do dinheiro não é moderna. Sociedades modernas, e isso se pode aprender com as doutrinas do dinheiro aqui discutidas, conhecem apenas dinheiro, o "valor" simbolizado, escassez "duplicada", que não tem ele mesmo valor. Em contrapartida, pode-se aprender com Marx que geralmente vale a pena considerar instituições sociais não no estado de seu funcionamento normal, e sim no estado de sua crise. Em relação ao nosso dinheiro, não é necessário, em vista desse exercício, olhar além da pré-história e da história inicial da República Federal [da Alemanha] por exemplo, quando havia ainda algo como mercados negros com cigarros servindo como moeda. Cigarros funcionam como equivalente universal, todos os preços das mercadorias eram apresentados em unidades de cigarro, cigarros eram objetos de troca preferencialmente desejáveis também para não-fumantes. Pode-se aprender dessa história que, quando desaba a "confiança" em uma cédula de papel impressa por uma autoridade estatal superior, emergencialmente se retorna de novo a um "dinheiro" que emerge espontaneamente, que, sendo produto do trabalho, é propriamente mercadoria. É fácil explicar por que isso acontece: de um lado, a ninguém ocorreria a ideia de trocar um objeto de valor por um outro objeto sem valor. Em uma crise do dinheiro, quando as 
"reservas de cobertura" para o meio, mencionadas por Parsons e Habermas, já não são suficientes, mostra-se, pois, que faz todo o sentido entender o dinheiro a partir da mercadoria - sobretudo se não se acredita na estabilidade das relações monetárias vigentes.

O específico da doutrina marxiana do dinheiro, a saber, entender o dinheiro não apenas como coisa, como mercadoria, mas a partir do trabalho, torna-se talvez mais visível quando se confronta esta abordagem com a ideia, acima esboçada, de uma hierarquia de controle cibernética. Em relação a essa hierarquia, a perspectiva de Marx é "de baixo" para "cima”, de um nível do sistema no qual muita energia e pouca informação é subsumida a um outro, que pode se limitar a tocar as teclas do "código de controle". O que, na linguagem do "código de controle", significa o fator de produção "trabalho", que é “evidentemente incluído na codificação" (LuHMANN, 1984, p. 310), significa o seguinte em uma outra linguagem: aqui são seres humanos que trabalham sob o comando de outros. Eles não são retratados como tais no código do dinheiro. Aqui Luhmann está absolutamente certo. Mas e se a retratação no código monetário como preço do fator trabalho não lhes convém, e se eles se defendem contra a subsunção à relação de dominação ligada àquela retratação?

Para uma teoria do dinheiro que assume a perspectiva daqueles que precisam trabalhar, há aqui em todo caso mais a ganhar do que nas doutrinas sociológicas do dinheiro acima consideradas. De fato, textos de Marx podem dar a alguns mero material para ruminar, mas de vez em quando isso poderia ter valido a pena: "Comparar o dinheiro com a linguagem é [...] falso. As ideias não são transformadas na linguagem de modo tal que sua peculiaridade é dissolvida e seu caráter social existiria ao lado delas na linguagem tal como os preços ao lado das mercadorias. As ideias não existem separadamente da linguagem. Ideias que precisam primeiro ser traduzidas de sua língua materna em uma língua estrangeira para circularem, para se tornarem permutáveis, oferecem uma analogia melhor; mas a analogia não está, então, na língua, mas na sua estrangeiridade" (MARX, 1953, p. 80). Naturalmente se pode discutir se a teoria monetária de Marx é consistente ao ponto de ela sustentar uma crítica da doutrina sociológica do dinheiro. Pode-se - com Luhmann - interpretá-la como forma obsoleta de crítica ou de denúncia do dinheiro que passa ao largo dele como "conquista evolutiva" que porta a autodiferenciação da economia como subsistema da sociedade, ignorando que uma retração dessa conquista condiciona o retorno a estruturas sociais estratificadas segundo uma forma de dominação hierárquica, estruturas que, para a "modernidade”, o princípio característico da diferenciação funcional já deve ter superado. Em contraposição, pode-se perguntar de volta, com Marx, se precisamente na função 
do "código do dinheiro" não é legível o fato de que a dominação, na "modernidade", apenas assumiu uma outra forma. Enquanto a sociologia pós-weberiana in toto parece admitir que a dominação é quase neutralizada pelo fato de que ela está em uma relação recíproca de aumento de liberdade - condicionada pela diferenciação funcional -, Marx afirma - precisamente na reflexão sobre as relações sociais pré-burguesas - que a dominação assume forma objetiva na sociedade burguesa, mas de modo algum seria neutralizada ou diminuída.

Aparentemente, o dinheiro oferece a possibilidade da liberdade formal, da emancipação individual: "O que todo indivíduo possui no dinheiro é a capacidade universal da troca, pela qual ele determina para si sua fração dos produtos sociais à sua escolha. Cada indivíduo possui o poder social no seu bolso sob a forma de uma coisa. Se a coisa é roubada de seu poder social, então você tem de entregar esse poder imediatamente ao poder da pessoa sobre a pessoa [...]. Os vínculos têm de ser organizados como vínculos políticos, religiosos, etc., tão logo o poder do dinheiro não seja o nexus rerum et hominum" (MARx, 1953, p. 986 ss). O problema dos sociólogos, contudo, é que eles não conseguem reconhecer a plena dimensão na qual o "poder do dinheiro" se tornou "o nexus rerum et hominum" - provavelmente porque eles acham que com isso sua ciência se tornaria supérflua em favor de uma economia especializada no dinheiro. No entanto, uma teoria econômica ameaçadora nesse sentido não existe na realidade, mas apenas na definição da situação feita pelos sociólogos. Daí a tentativa de encenar, ao lado do "poder do dinheiro" como meio, uma reanimação teórica dos "vínculos políticos, religiosos, etc.” na teoria dos meios.

Em contraste, não é implausível quando Marx concebe o dinheiro como substituto para o poder, influência, vínculo de valores, etc. Em vez de jogar tais “meios" contra o dinheiro, seria mais interessante perguntar até que ponto o dinheiro assumiu "o lugar dos variados meios vinculantes da humanidade" (MARX, 1953, p. 874). Em nossa sociedade, em todo caso, a “coerção muda das relações econômicas", que é comunicada por meio do dinheiro, é suficiente para o pior. Quem não tem nenhum sabe melhor.

\section{REFERÊNCIAS}

BECKERATH, Erwin von et al. (ed.) Handwörterbuchder Sozialwissenschaften. Stuttgart: Gustav Fischer, 1965.

DöBLIN, Alfred. Babylonische Wanderung. München, 1984.

GadAMER, Hans-Georg. (ed.) Das Problem der Sprache. München: W. Fink, 1967.

FrESE, Jürgen. Sprechen als Metapher für Handels. In: GADAMER, Hans-Georg. (ed.) op. cit. 
GanSSmann, Heiner. On the reconstruction of economics as a social science. iskussionsbeiträge zur Politischen Ökonomie, $\mathrm{n}^{\circ}$ 29, Bielefeld, 1979.

. On money and value. (Manuscrito não publicado), Berlin, 1983.

. KommunikationundReproduktion, in: Leviathan, v. 14, n. 1, p. 143-156, 1986.

Habermas, Jürgen. Handlung und System: Bemerkungen zu Parsons' Medientheorie, in: Schluchter, Wolfgang. Verhalten, Handeln und System: Talcott Parsons` Beitrag zurEntwicklung der Sozialwissenschaften. Frankfurt a.M.: Suhrkamp, 1980, p. 68-105.

Theorie des kommunikativen Handelns, 2 v. Frankfurt a.M.:Suhrkamp, 1981. KAMLAH, Wilhelm. Sprachliche Handlungsschemata, in: GADAMER, H. G. (ed.), op. cit. Luhmann, Niklas. Knappheit, Geld und die bürgerliche Gesellschaft, in: Jahrbuch für Sozialwissenschaft, v. 2, n. 23, 1972.

Das sind Preise: Ein soziologisch-systemtheoretischer Klärungsversuch, in:

Soziale Welt, v. 2, n. 34, p. 153-170, 1983.

Die Wirtschaft der Gesellschaft als autopoietisches System, in:Zeitschrift für Soziologie, v. 4, p. 366-379, 1982.

MARX, Karl. Grundrisse der Kritik der politischen Ökonomie. Berlin: Dietz Verlag, 1953. Zur Kritik der politischen Ökonomie, in: Marx-Engels-Werke, v. 13, Berlin: Dietz Verlag, 1961.

MiLl, John Stuart. Principles of political economy, 2 v. London, 1900.

O'NEIL, John. For Marx against Althusser. Washington: UPA, 1982.

Parsons, Talcott. The structure of social action. New York: McGrawHill, 1937.

. The social system. Glencoe: Free Press, 1951.

Societies. Englewood Cliffs: Prentice-Hall, 1966.

Action theory and the human condition. New York: Free Press, 1978.

Schluchter, Wolfgang. (ed.) Verhalten, Handeln, System. Frankfurt a.M.: Suhrkamp, 1980. Simmel, Georg. Philosophie des Geldes. Leipzig: Duncker/Humboldt, 1907.

WEBER, Max. Wirtschaft und Gesellschaft. Tübingen: Mohr Verlag, 1972.

Wiese, Leopold von. Artikel: Wirtschaftssoziologie, in: Beckerath, E. et al. (ed) op. cit. WILDEN, Anthony. System and structure: Essays in communication and exchange. $2^{\mathrm{a}}$ ed. London: Tavistock, 1980.

Recebido: 15/12/2020 | Aprovado: 02/02/2021 